\title{
ASSOCIATIONS BETWEEN INFLAMMATORY MARKERS AND BONE MINERAL DENSITY IN LEAN PUBERTAL GIRLS
}

\author{
JAAK JÜRIMÄE ${ }^{1}$, ANNA-LiISA TAMM ${ }^{2}$, LiINA REMMEL ${ }^{1}$, \\ VAllo TillmanN ${ }^{3}$ \\ ${ }^{1}$ Institute of Sport Sciences and Physiotherapy, Faculty of Medicine, \\ University of Tartu, Tartu, Estonia \\ ${ }^{2}$ Tartu Health Care College, Tartu, Estonia \\ ${ }^{3}$ Institute of Clinical Medicine, Faculty of Medicine, University of Tartu, Tartu, Estonia
}

\begin{abstract}
We investigated whether common inflammatory markers are associated with bone accumulation in lean pubertal girls. Thirty-four 10-12-yearold lean girls at pubertal stages $2-4$ were studied. Twelve inflammatory parameters [interleukin (IL)-2, IL-4, IL-6, IL-8, IL-10, vascular endothelial growth factor, interferon-gamma (IFN- $\gamma$ ), tumour necrosis factoralpha, IL-1 $\alpha$, IL-1 $\beta$, monocyte chemotactic protein-1 (MCP-1) and epidermal growth factor] were measured from plasma samples. Whole body (WB), lumbar spine (LS) and femoral neck (FN) bone mineral density (BMD), and WB bone mineral content (BMC) were assessed by DXA. Plasma IFN- $\gamma$ concentration was negatively correlated $(\mathrm{p}<0.05)$ with WB BMC $(r=-0.45)$, WB BMD $(r=-0.46)$ and FN BMD $(r=-0.43)$. In addition, plasma IL-6 $(r=-0.37 ; \mathrm{p}<0.05)$, IL- $1 \alpha(\mathrm{r}=-0.40 ; \mathrm{p}<0.05)$ and MCP-1 $(\mathrm{r}=-0.38 ; \mathrm{p}<0.05)$ concentrations were also negatively correlated to measured BMD values. The stepwise regression analysis showed that IFN- $\gamma$ alone and together with IL-1 $\alpha$ explained $18.6 \%$ and $27.6 \%$, respectively, of the variability in WB BMD, while IL- $1 \alpha$ and MCP- 1 together explained $25.5 \%$ of the variability in LS BMD, and IL-1 $\alpha$ together with IFN- $\gamma$ explained $34.1 \%$ of the variability in FN BMD. In conclusion, plasma IFN- $\gamma$, IL-6, IL- $1 \alpha$ and MCP- 1 concentrations were associated with $\mathrm{BMD}$ variables, suggesting that these cytokines may participate in bone accumulation in lean pubertal girls.
\end{abstract}

Keywords: inflammatory markers, lean girls, puberty, bone accumulation 


\section{INTRODUCTION}

Puberty is an important period for bone mineral accrual in children over a relatively brief period, influenced by genetic potential, endocrine status, nutritional factors, body composition and physical activity (PA) $[6,10,15]$. Puberty is also a period when a marked decline in PA occurs, which is typically accompanied by a significant weight gain [14]. Childhood obesity has been positively linked to bone mineral density (BMD) and bone mineral content (BMC) in sedentary pubertal girls $[6,15]$. A positive effect of fat mass (FM) on bone mineral accrual has been attributed to a combination of mechanical load exerted on the skeleton by FM [6] and by the adipose tissue modulated blood biochemical signals [15]. We have shown that relatively low adiposity in boys in addition to decline in PA is a risk factor for low bone mineral accrual in puberty [28].

It has been previously shown that excess adiposity has been related to low-grade systemic inflammation $[2,21]$, and many inflammatory parameters such as interleukin (IL)-6, IL-8, interferon-gamma (IFN- $\gamma$ ), monocyte chemotactic protein-1 (MCP-1) and high-sensitive C-reactive protein (hsCRP) are elevated in overweight and obese children [26]. While many of these markers have been inversely related to adult bone health $[1,4$, 13], there is a very limited knowledge of the possible role of inflammatory markers in the association between body adipose tissue and bone mineral accrual in normal children during growth and maturation $[9,27]$. Some inflammatory markers have been reported to be negatively associated with bone mineral values in normal weight children $[9,27]$, while in contrast a positive correlation between circulating IFN $-\gamma$ concentration and wholebody (WB) BMD was found among overweight pubertal boys [27]. It was speculated that IFN- $\gamma$ may contribute to low-grade inflammation in obesity [26] and could be a link between increased FM and higher BMD in overweight pubertal boys [27], whereas the knowledge about the role of different inflammatory markers in lean normally growing children is limited. To our best knowledge, the possible role of different inflammatory markers in bone health in lean female girls during puberty has not been studied before. The aim of the present study was to investigate the possible associations between a panel of simultaneously measured 12 inflammatory markers and bone mineral parameters in lean pubertal girls. 


\section{MATERIALS AND METHODS}

\section{Participants}

Thirty-four healthy Estonian pubertal girls participated in this study. The participants were recruited from physical education classes at the local secondary schools that they had twice a week. Participation only in school physical education classes was inclusion criteria for subjects as they did not participate in any training groups. None of the participants was receiving any medications or had any recent acute illnesses or a history of bone or renal diseases. All procedures were approved by the Medical Ethics Committee of the University of Tartu, Estonia and were explained to the children and their parents, who signed an informed consent form.

\section{Anthropometry and sexual maturation}

Body height was measured with the use of a Martin metal anthropometer to the nearest $0.1 \mathrm{~cm}$ according to the standard technique, and body mass was measured with minimal clothing to the nearest $0.05 \mathrm{~kg}$ with a medical electronic scale (A\&D Instruments Ltd., Abingdon, UK). Body mass index (BMI) was also calculated $\left(\mathrm{kg} / \mathrm{m}^{2}\right)$. Pubertal development was assessed by self-report using an illustrated questionnaire according to the Tanner classification method [25], which has been validated [17] and used previously in our laboratory in different studies $[8,11,19]$. The girls were given photographs, figures and descriptions of breast and pubic hair development stages and asked to choose the one that most accurately reflected their appearance. In the case of discrepancies between the two variables, greater emphasis for the determination of the Tanner stage was placed on the degree of breast development.

\section{Bone mineral assessments}

Bone mineral density (BMD, $\mathrm{g} / \mathrm{cm}^{2}$ ) of the whole body (WB), lumbar spine (LS), femoral neck (FN), and the WB bone mineral content (BMC) were measured by DXA using the DPX-IQ densitometer (Lunar Corporation, Madison, Wisc., USA) equipped with proprietary software, version 3.6 [11, 20]. Participants were scanned in light clothing while lying flat on their backs with arms on their sides. The fast scan mode and standard subject positioning were used for whole-body measurements and analysis was performed using an extended analysis option. The same experienced examiner evaluated all DXA measurements and results. Coefficients of variation (CVs) for BMC and BMD measurements were less than $2 \%$. 


\section{Blood analysis}

Venous blood samples were drawn between 7:30 and 8:30 a.m. after an overnight fast from an antecubital vein with the participant sitting in the upright position. The plasma was separated and frozen at $-20^{\circ} \mathrm{C}$. All plasma samples were measured simultaneously within 6 months of collection. The following markers of inflammation were measured: interleukin (IL)-2, IL-4, IL-6, IL-8, IL-10, vascular endothelial growth factor (VEGF), interferon-gamma (IFN- $\gamma$ ), tumour necrosis factor-alpha (TNF- $\alpha$ ), IL-1 $\alpha$, IL-1 $\beta$, monocyte chemotactic protein-1 (MCP-1) and epidermal growth factor (EGF) [26]. The Cytokine and Growth Factors Special High-Sensitivity Array of the Biochip system (Randox Laboratories Ltd, Crumlin, UK) was used for simultaneous quantitative detection of multiple, related cytokine immunoassays in parallel from a single sample. None of the inflammation markers were below detection limits. For all measured markers, intra-assay CV was 5.1-8.5\%, and inter-assay CV was between 5.8-9.9\% [26].

\section{Statistical analysis}

All statistical analyses were performed using SPSS, version 20.0 (SPSS Inc, Chicago. IL, USA). Data are presented as mean \pm standard derivation (SD) and are also described by median and interquartile range. Relationships between inflammatory markers and measured bone indices were assessed by Pearson correlation analysis. Stepwise multiple regression analysis was performed to determine the independent effect of BMI and 12 inflammatory markers on measured BMC and BMD variables [27]. The level of significance was set at $\mathrm{p}<0.05$.

\section{RESULTS}

The main physical examination and bone mineral data of participants as well as the results of serum inflammatory biomarkers are presented in Table 1. Nineteen girls were at pubertal stage 2, 12 girls at pubertal stage 3 and 3 girls at pubertal stage 4 . Plasma IFN- $\gamma$ concentration was negatively correlated $(\mathrm{p}<0.05)$ with WB BMC $(\mathrm{r}=-0.45)$, WB BMD $(\mathrm{r}=-0.46)$ and FN BMD $(\mathrm{r}=-0.43)$. In addition, IL-6 was negatively correlated $(\mathrm{p}<0.05)$ with WB BMC ( $\mathrm{r}=-0.37)$, WB BMD ( $\mathrm{r}=-0.41)$, LS BMD ( $\mathrm{r}=-0.43)$ and FN BMD $(\mathrm{r}=-0.39)$, while IL-1 $\alpha$ was negatively related to $(\mathrm{p}<0.05)$ WB BMD $(\mathrm{r}=-0.40)$, LS BMD $(\mathrm{r}=-0.44)$ and FN BMD $(\mathrm{r}=-0.51)$. Plasma MCP-1 was also correlated to LS BMD $(r=-0.38 ; \mathrm{p}<0.05)$. All other correlations between 12 inflammatory markers and bone mineral values were not significant. 
The stepwise multiple regression analysis demonstrated that BMI was the most significant predictor of WB BMC, explaining $25.1 \%$ of the variability in WB BMC, while IFN- $\gamma$ alone and together with IL-1 $\alpha$ explained $18.6 \%$ and $27.6 \%$, respectively, of the variability of WB BMD in lean pubertal girls (Table 2). In addition, IL- $1 \alpha$ explained $16.9 \%$ and $23.6 \%$ of the variability in LS and FN BMD values, respectively. While IL-1 $\alpha$ and MCP-1 together explained $25.5 \%$ of the variability in LS BMD, and IL- $1 \alpha$ together with IFN- $\gamma$ explained $34.1 \%$ of the variability in FN BMD (Table 2).

Table 1. Physical and inflammatory biomarkers characteristics of the participants $(n=34)$.

\begin{tabular}{|c|c|c|}
\hline Variable & Mean \pm SD & Median (interquartile range) \\
\hline Age (yrs) & $11.2 \pm 0.5$ & $11.3(10.7-11.7)$ \\
\hline Height $(\mathrm{cm})$ & $148.1 \pm 5.7$ & $147.9(143.9-153.9)$ \\
\hline Body mass (kg) & $39.8 \pm 7.3$ & $39.9(33.4-44.6)$ \\
\hline BMI $\left(\mathrm{kg} / \mathrm{m}^{2}\right)$ & $18.2 \pm 2.9$ & $17.9(15.7-19.6)$ \\
\hline WB BMC (g) & $1433.7 \pm 254.2$ & $1403.5(1231.6-1629.3)$ \\
\hline WB BMD $\left(\mathrm{g} / \mathrm{cm}^{2}\right)$ & $0.925 \pm 0.059$ & $0.925(0.877-0.963)$ \\
\hline LS BMD $\left(\mathrm{g} / \mathrm{cm}^{2}\right)$ & $0.836 \pm 0.123$ & $0.831(0.741-0.902)$ \\
\hline FN BMD $\left(\mathrm{g} / \mathrm{cm}^{2}\right)$ & $0.832 \pm 0.121$ & $0.801(0.753-0.902)$ \\
\hline IL-2 (pg/ml) & $2.1 \pm 2.3$ & $2.1(1.2-5.1)$ \\
\hline IL-4 (pg/ml) & $2.2 \pm 1.1$ & $2.0(1.6-2.5)$ \\
\hline IL-6 (pg/ml) & $1.8 \pm 2.1$ & $0.9(0.6-2.0)$ \\
\hline IL-8 (pg/ml) & $11.5 \pm 5.6$ & $10.6(6.4-14.3)$ \\
\hline IL-10 (pg/ml) & $1.9 \pm 1.7$ & $1.4(0.8-2.5)$ \\
\hline VEGF (pg/ml) & $66.2 \pm 42.8$ & $48.9(38.3-90.2)$ \\
\hline IFN- $\gamma(\mathrm{pg} / \mathrm{ml})$ & $0.9 \pm 0.8$ & $0.7(0.3-1.3)$ \\
\hline TNF-a (pg/ml) & $3.6 \pm 1.4$ & $3.7(2.7-4.1)$ \\
\hline IL-1a (pg/ml) & $0.3 \pm 0.2$ & $0.2(0.1-0.3)$ \\
\hline $\mathrm{IL}-1 \beta(\mathrm{pg} / \mathrm{ml})$ & $2.0 \pm 1.2$ & $1.6(1.3-2.4)$ \\
\hline MCP-1 (pg/ml) & $152.0 \pm 46.4$ & $142.7(116.6-182.5)$ \\
\hline $\mathrm{EGF}(\mathrm{pg} / \mathrm{ml})$ & $36.4 \pm 14.9$ & $37.1(27.5-44.1)$ \\
\hline
\end{tabular}


Table 2. Results of stepwise multiple regression analysis with whole body BMC, whole body BMD, lumbar spine BMD and femoral neck BMD as dependent variables, and BMI and measured 12 inflammatory markers as independent variables $\left(R^{2} \times 100 ; p<0.05\right)$.

\begin{tabular}{llcc}
\hline Dependent variables & \multicolumn{1}{l}{ Independent variables } & $\mathbf{R}^{2} \times 100$ & $\mathbf{p}$ \\
\hline \multirow{2}{*}{ Whole body BMC } & BMI & 25.1 & 0.001 \\
\cline { 2 - 4 } & BMI, IL-1 $\beta$ & 36.0 & 0.0001 \\
\hline \multirow{2}{*}{ Whole body BMD } & IFN- $\gamma$ & 18.6 & 0.006 \\
\cline { 2 - 4 } & IFN- - IL-1a & 27.6 & 0.003 \\
\hline \multirow{2}{*}{ Lumbar spine BMD } & IL-1a & 16.9 & 0.009 \\
\cline { 2 - 4 } & IL-1a, MCP-1 & 25.5 & 0.004 \\
\hline \multirow{2}{*}{ Femoral neck BMD } & IL-1a & 23.6 & 0.002 \\
\cline { 2 - 4 } & IL-1a, IFN- $\gamma$ & 34.1 & 0.001 \\
\hline
\end{tabular}

\section{DISCUSSION}

Possible associations of 12 inflammatory parameters with bone mineral characteristics were studied in 34 lean pubertal girls. Plasma IFN- $\gamma$, IL-6, IL- $1 \alpha$ and MCP-1 concentrations were negatively associated with different bone mineral variables, suggesting that these pro-inflammatory cytokines may participate in bone accumulation in lean pubertal girls.

We found a negative independent association of plasma IFN- $\gamma$ concentration with WB BMD (see Table 2). In addition, circulating IFN- $\gamma$ level was also inversely correlated with other measured BMC and BMD values. To our best knowledge, no studies have previously investigated the associations between plasma IFN- $\gamma$ concentration and BMD variables in girls during puberty. In accordance with the results of the present study, markers of IFN- $\gamma$-mediated inflammation were inversely related to bone mineral values in the healthy elderly, but not middle-aged men and women [1], while other study demonstrated no relationship between IFN $-\gamma$ concentration and BMD variables in healthy people [16]. In our previous study, we found that serum IFN- $\gamma$ concentration was positively associated with WB BMD in overweight boys, while no such a relationship was found in normal weight boys [27]. It was suggested that IFN- $\gamma$ may contribute to inflammation in obesity and could be a link between increased FM and higher WB BMD in pubertal boys [27]. As circulating IFN- $\gamma$ concentrations in studied pubertal lean girls were much lower than corresponding values in overweight pubertal boys [27], it is likely that the association between IFN- $\gamma$ and BMD in growing children 
is dependent on the amount of body adiposity. However, further studies in subjects with wide range of BMI values are needed before any conclusions can be drawn.

IFN- $\gamma$ is produced locally in bone tissue by cells of immune origin and mesenchymal stem cells $[5,24]$. It can either inhibit osteoclast formation or enhance osteoclastogenesis according to the conditions to which the osteoclast precursors are exposed [24]. In addition, IFN- $\gamma$ also promotes the fusion of pre-fusion osteoclasts to form multinucleated mature osteoclasts [29]. In an animal model that mimics inflammation and estrogen deficiency, IFN- $\gamma$ indirectly stimulates osteoclast formation and bone loss by stimulating antigen-dependent $\mathrm{T}$ cell activation [7]. Further studies indicated that RANKL upregulation is mediated by IFN- $\gamma$ inducible protein-10 in T-cells [12]. A study by Ayon Haro et al. [3] confirmed that IFN- $\gamma$ together with lipopolysaccharides enhanced osteoclast formation and therefore likley increased bone resorption. Our results are in accordance with these findings [3], where IFN- $\gamma$ was inversely associated with bone mineral variables in lean pubertal girls. However, IFN- $\gamma$ receptor knockout mice exhibited a reduction in bone volume and significant changes in cortical and trabecular bone structure typical for osteoporotic phenotype [5]. Administration of IFN- $\gamma$ to wild-type ovariectomized female mice improved bone mass and microarchitecture and rescued osteoporosis [5]. Taken together, it has been suggested that these conflicting results may indicate a difference between local versus systemic impact of IFN- $\gamma$ on bones [1].

We also found that plasma IL-6, IL-1 $\alpha$ and MCP-1 levels were negatively correlated with measured bone mineral variables indicating that these pro-inflammatory cytokines participate in bone remodelling. It has been proposed that circulating IL-6 may play a role in the mechanism leading to either a decrease or lack of the expected increase in BMD during adolescence [18]. Specifically, inflammatory cytokines such as IL-1, IL-6 and TNF- $\alpha$ induce bone resorption by controlling the differentiation and activity of osteoblasts and osteoclasts, which subsequently leads to increased bone turnover and decreased BMD [13, 22, 23]. In healthy premenopausal women, the production of IL-1, IL-6 and TNF- $\alpha$ in peripheral blood mononuclear cells was positively correlated with vertebral bone loss [22], whereas serum IL-6 concentration predicted femoral bone loss [23]. To our best knowledge, there have been no studies investigating the possible association between MCP-1 and BMD in pubertal girls. Our study found a negative correlation between plasma MCP-1 and LS BMD. The recent study by Yan et al. [30], where mice deficient in MCP-1 exhibited increases in vertebrae trabecular 
thickness and BMD compared to wild-type mice, supported our negative correlation between MCP-1 and LS BMD in lean pubertal girls.

In conclusion, plasma IFN- $\gamma$, IL-6, IL- $1 \alpha$ and MCP- 1 concentrations were negatively associated with bone mineral variables, suggesting that these cytokines may participate in bone accumulation in lean pubertal girls.

\section{ACKNOWLEDGEMENT}

This study was supported by Estonian Ministry of Education and Science institutional (IUT 20-58) and personal (1382P) research grants.

\section{REFERENCES}

1. Apalset EM, Gjesdal CG, Ueland PM, Midttun O, Ulvik A, Eide GE, Meyer K, Tell GS. (2014) Interferon (IFN)- $\gamma$-mediated inflammation and the kynurenine pathway in relation to bone mineral density: the Hordaland Health Study. Clin Exp Immunol, 176: 452-460.

2. Aquilar MJ, Gonzalez-Jimenez E, Antelo A, Perona JS. (2013) Insulin resistance and inflammation markers: correlations in obese adolescents. J Clin Nurs, 22: 2002-2010.

3. Ayon Haro ER, Ukai T, Yokoyama M, Kishimoto T, Yoshinaga Y, Hara Y. (2011) Locally administered interferon-gamma accelerates lipopolysaccharide-induced osteoclastogenesis independent of immunohistological RANKL upregulation. J Periodontal Res, 46: 361-373.

4. Ding C, Parameswaran V, Udayan R, Burgess J, Jones G. (2008) Circulating levels of inflammatory markers predict change in bone mineral density and resorption in older adults: a longitudinal study. J Clin Endocrinol Metab, 93: 1952-1958.

5. Duque G, Huang DC, Dion N, Macoritto M, Rivas D, Li W, Yang XF, Li J, Lian J, Marino FT, Barrelet J, Lascau V, Deschenes C, Ste-Marie LG, Kremer R. (2011) Interferon-gamma plays a role in bone formation in vivo and rescues osteoporosis in overectomized rat. J Bone Miner Res, 26: 1472-1483.

6. El Hage R, Moussa E, Jacob C. (2010) Bone mineral content and density in obese, overweight, and normal-weight sedentary adolescent girls. J Adolesc Health, 47: 591-595.

7. Gao Y, Grassi F, Ryan MR, Terauchi M, Page K, Yang X, Weitzmann MN, Pacifici R. (2007) IFN-gamma stimulates osteoclast formation and bone loss in vivo via antigen-driven $\mathrm{T}$ cell activation. J Clin Invest, 177: 122-132.

8. Gruodyté R, Jürimäe J, Cicchella A Stefanelli C, Passariello C, Jürimäe T. (2010) Adipocytokines and bone mineral density in adolescent female athletes. Acta Paediatr, 99: 1879-1874. 
9. Hanks LJ, Casazza K, Alvarez JA, Fernandez JR. (2010) Does fat fuel the fire: independent and interactive effects of genetic, physiological, and environmental factors on variations in fat deposition and distribution across populations. J Pediatr Endocrinol Metab, 23: 1233-1244.

10. Jürimäe J. (2010) Interpretation and application of bone turnover markers in children and adolescents. Curr Opin Pediatr, 22: 494-500.

11. Jürimäe J, Tillmann V, Cicchella A, Stefanelli C, Võsoberg K, Tamm AL, Jürimäe T. (2016) Increased sclerostin and preadipocyte factor-1 levels in prepubertal rhythmic gymnasts: associations with bone mineral density, body composition, and adipocytokine values. Osteopor Int, 27: 1239-1243.

12. Lee EY, Seo M, Juhnn YS, Kim JY, Hong YJ, Lee YJ, Lee EB, Song YW. (2011) Potential role and mechanism of IFN-gamma inducible protein-10 on receptor activator of nuclear factor kappa-B ligand (RANKL) expression in rheumatoid arthritis. Arthritis Res Ther, 13: R104.

13. Lim HS, Park YH, Kim SK. (2016) Relationship between serum inflammatory marker and bone mineral density in healthy adults. J Bone Metab, 23: 27-33.

14. Lätt E, Mäestu J, Ortega FB, Rääsk T, Jürimäe T, Jürimäe J. (2015) Vigorous physical activity rather than sedentary behaviour predicts overweight and obesity in pubertal boys: A 2-year follow-up study. Scand J Public Health, 43: 276-282.

15. Maimoun L, Georgopoulos NA, Sultan C. (2014) Endocrine disorders in adolescent and young female athletes: impact on growth, menstrual cycles, and bone mass acquisition. J Clin Endocrinol Metab, 99: 4037-5000.

16. Marques EA, Mota J, Viana JL, Tuna D, Figueiredo P, Guimaraes JT, Carvalho J. (2013) Response of bone mineral density, inflammatory cytokines, and biochemical bone markers to a 32-week combined loading exercise programme in older men and women. Arch Geront Geriatr, 57: 226-233.

17. Matsudo SMM, Matsudo VKR. (1994) Self-assessment and physician assessment of sexual maturation in Brazilian boys and girls: concordance and reproducibility. Am J Hum Biol, 6: 451-455.

18. Misra M, Klibanski A. (2006) Anorexia nervosa and osteoporosis. Rev Endocrinol Metab Disorders, 7: 91-99.

19. Pomerants T, Tillmann V, Jürimäe J, Jürimäe T. (2006) Relationship between ghrelin and anthropometrical, body composition parameters and testosterone levels in boys at different stages of puberty. J Endocrinol Invest, 29: 962-967.

20. Pomerants T, Tillmann V, Jürimäe J, Jürimäe T. (2007) The influence of serum ghrelin, IGF axis and testosterone on bone mineral density in boys at different stages of sexual maturity. J Bone Miner Metab, 25: 193-197.

21. Russell M, Mendes N, Miller KK, Rosen CJ, Lee H, Klibanski A, Misra M. (2010) Visceral fat is a negative predictor of bone density measures in obese adolescent girls. J Clin Endocrinol Metab, 95: 1247-1255. 
22. Salmone LM, Whiteside T, Friberg D, Epstein RS, Kuller LH, Cauley JA. (1998) Cytokine production and bone mineral density at the lumbar spine and femoral neck in premenopausal women. Calcif Tissue Int, 63: 466-470.

23. Scheidt-Nave C, Bismar H, Leidig-Bruckner G, Woitge H, Seibel MJ, Ziegler R, Pfeilschifter J. (2001) Interleukin 6 is a major predictor of bone loss in women specific to the first decade past menopause. J Clin Endocrinol Metab, 86: 20322042.

24. Takayanagi H, Sato K, Takaoka A, Taniguchi T. (2005) Interplay between iterferon and other cytokine systems in bone metabolism. Immunol Rev, 208: 181193.

25. Tanner J. (1962) Growth at adolescence. 2nd ed. Oxford, Blackwell Scientific Publications.

26. Utsal L, Tillmann V, Zilmer M, Mäestu J, Purge P, Jürimäe J, Saar M, Lätt E, Maasalu K, Jürimäe T. (2012) Elevated serum IL-6, IL-8, MCP-1, CRP and IFN- $\gamma$ levels in 10-to 11-year-old boys with increased BMI. Horm Res Paediatr 78:31-39.

27. Utsal L, Tillmann V, Zilmer M, Mäestu J, Purge P, Saar M, Lätt E, Jürimäe T, Maasalu K, Jürimäe J. (2014) Serum interferon gamma concentration is associated with bone mineral density in overweight boys. J Endocrinol Invest, 37: 175-180.

28. Vaitkeviciute D, Lätt E, Mäestu J, Jürimäe T, Saar M, Purge P, Maasalu K, Jürimäe J. (2014) Physical activity and bone mineral accrual in boys with different body composition parameters during puberty: a longitudinal study. PLoS One, 9(10): e107759.

29. Xiong Q, Zhang L, Ge W, Tang P. (2016) The roles of interferons in osteoclasts and osteoclastogenesis. Joint Bone Spine, 83: 276-228.

30. Yan L, Nielsen FH, Sundaram S, Cao J. (2017) Monocyte chemotactic protein-1 deficiency attenuates and high-fat diet exacerbates bone loss in mice with Lewis lung carcinoma. Oncotarget, 8: 23303-23311.

\section{Corresponding author:}

Professor Jaak Jürimäe, $\mathrm{PhD}$

Institute of Sport Sciences and Physiotherapy, Faculty of Medicine

University of Tartu

18. Ülikooli St. Tartu 50090, Estonia

Email: jaak.jurimae@ut.ee 